\title{
A Deep Perspective on Female Senior Intellectuals under Modern Circumstances in the Marriage of Miss $\mathrm{Su}$
}

\author{
Lin Jia \\ Hebei University \\ Baoding, China \\ 18832953265@163.com
}

\begin{abstract}
The Marriage of Miss $\mathrm{Su}$ is one of Liuliu's short stories. The story describes an excellent woman named Luoyan Su who spares no efforts to find an ideal husband. Finally she gets married with a man she is satisfied with, even though the marriage is based on cheat. Miss Su exerts all over skill to pursuit her happiness, however, marriage shuts her out. Through Miss Su's situation, we can have a glimpse of the situation encountered by female senior intellectuals. Women's issues are getting more and more attention around the world. At the same time, society's value orientation for women through the standard of spouse selection can make a big difference. When discussed female senior intellectuals, the paper analyzes by the method of comparative study and survey analysis. Compared to the past, women's subjective consciousness has made a great progress, and there is still a long way to go if women want to develop independently. The paper suggests that women are sensible and they should try harder to fight for their own rights.
\end{abstract}

Keywords - the portrayal of women; female senior intellectuals

\section{INTRODUCTION}

The Marriage of Miss $\mathrm{Su}$ [1]is a short story written by an authoress named Liuliu. The story describes an outstanding woman named Luoyan Su. In order to find an ideal husband and get married, Miss Su gives up her teaching position in British university and returns to the motherland. After several times of failed blind date, she successfully catches a fresh meat in IT industry and gets married even though everyone don't rate it at all. In this way, Miss Su completes a great event in her life at the age of thirty-three. She never dreams of her boyfriend was an "undercover" who was arranged by the matrimonial agency. Even though Miss Su exerts all over skill to pursuit her happiness, marriage shuts her out.

\section{THE FEMALE PORTRAYAL OF MISS SU}

The portrayal of Miss Su is different from previous female senior intellectuals. The portrayal of Miss $\mathrm{Su}$ is vivid and lively. She is a doctor of law in Oxford with agile mind, professional judgement and aggressive action. And she works in a university in Britain. Meanwhile, Miss Su is a shy and easy-going girl who keens to blind date and eagers to get marry. This is different from the previous portrayal of female senior intellectuals. Female doctors and professors in previous literary works more or less proud, methodical, boring and even if it is not understood by society, it will be taken for granted that others have not reached the heights they have attained.
Even some of them are too self-centered. For example, Qingli Wen plays a professor who not only requires her girlfriends around her, but also her girlfriends' family in The 1.0 Age of Girlfriend. In view of this, Miss $\mathrm{Su}$, with high educational background and high ability, also has the characteristics of being easy-going and interesting. At first glance, it seems difficult to pick out any big faults from Luoyan Su. Even so, she still worries about how to find an ideal husband and get married.

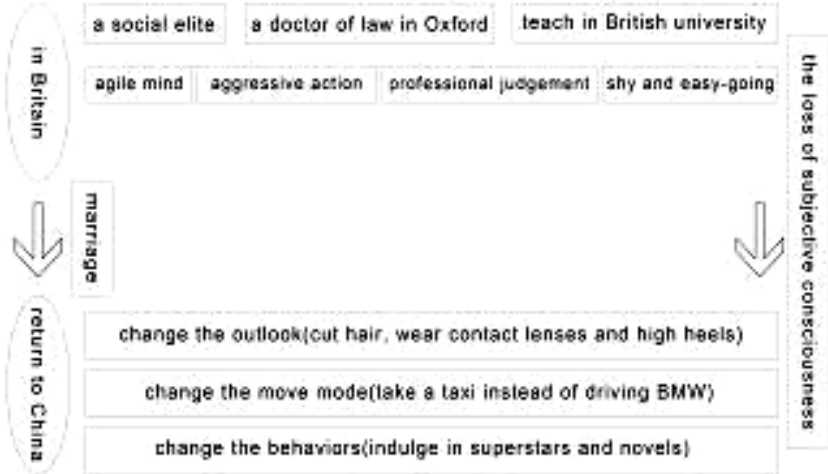

Fig. 1. The Change of Miss Su

As the figure shows, Miss Su gets her head down to cater to others and spares no efforts to get a fresh meat in IT industry eight years younger than her. To cater to the handsome man, Miss Su changes all her styles. She cuts her hair into classic Korean style instead of neat one, wears contact lenses instead of glasses, high heels instead of flat bottom plastic slippers, T-shirt and hot pants instead of suits. Not only that, she takes a taxi instead of driving BMW herself. She dresses like that only to get Charlene's signature with her boyfriend. As a partner, what she did and dressed really surprises people around her. Miss Su's previous colleagues analyze her failure of finding the right person to marry is her way of dressing and doing other things and that's why she made all such changes. Therefore, Miss $\mathrm{Su}$ makes changes. Besides, she indulges in star-chasing, Japanese anime and cross fiction which are so different from what she did before. Even with a high degree of education and ability, Miss Su still cannot escape the subconscious patriarchal society thinking and what she did is a manifestation of loss subject 
consciousness. Miss Su says that marriage is a systematic project and it is possible to lose all of her business only for a wrong step. She wants to manage her marriage as if she were running her business. In fact, Miss Su believes that marriage is more difficult than business and one should do it for a lifetime. It is not wrong that Miss Su regards marriage as a much more systematic project than a career, however, the pursuit of marriage at all costs is a loss of self.

Miss Su gave up her position and turned into a woman who was deeply penetrated with conventional thought, which is criticized by feminists [2]. As Woolf says, women must have a fixed income and a room of their own. Only in this way, can they have the freedom to live their own life [3]. The heroine in the Marriage of Miss $\mathrm{Su}$ had a fixed income, and she had the freedom to choose which life to live. Unfortunately, Miss Su becomes caught in a whirlpool of marriage. She is eager to marry and goes out of her room. With the development of feminism, more and more women are saved from the jaws of marriage [4]. It is noteworthy that what changes Miss Su. Who shall be responsible for this incident? Women should try their best to defend their rights.

\section{THE ABNORMAL RELATIONSHIP WITH BOYFRIEND}

We could learn a lot from the abnormal relationship between Miss $\mathrm{Su}$ and her boyfriend. In the novel, the little handsome man never shows his face to readers and readers can only surmise what happened to the little man through Miss Su's behavior. Miss Su believes that the little man is once-ina-lifetime. As a result of this, Miss Su does something crazy that doesn't match her knowledge and experience. What's more, people want to appreciate the wedding photos but they are not satisfied. Instead, they receive some obscure photos: the first photo is the man's hand holding the woman's hand with a diamond ring shining in the ring finger, the second photo is two feet on the beach in the sunset, the third photo is a silhouette of two shoulders, the fourth photo is two hands surrounding on the stomach, etc. Last but not least, the most implicit photo is erotic with a couple of underpants in a messy bed. All of these tell us that Miss Su protects the little man very well. Only when all of them promise they don't have any interest in this man, Miss $\mathrm{Su}$ takes out one photo with shy intensity. Even if the little handsome man is called into question, Miss Su defends him every time. Miss Su always believes that the little handsome man would grow into a man sooner or later. At the end of the novel, the little man looms into view and he walks into the finance department of the matrimonial agency. It's hard to imagine how Miss Su would react to such terrible situation.

\section{THE TRAGIC END}

The author designs a tragic end which is intriguing. Xiaopei seeks help from matrimonial agency and she is ready to wait for the right man. Suggestion is accepted, and everyone come to help her fill out the form. At the same time, the little man comes into view. He drives Miss Su's car and parks, walks into the finance department and swipes a golden card. The author brings an abrupt halt to the story. That's the end affords much food for thought. The crowd is puzzled and they don't know how to react, go back and warn Miss Su or ignore it? There is no definite answer to everyone's reaction. The one thing we can be sure about is that Miss $\mathrm{Su}$ is cheated by the so-called little handsome man. The man who is prized by Miss $\mathrm{Su}$ is arranged by the matrimonial agency. From the behavior of Miss Su, she classes herself as being intelligent and impelled that little man to marry her. Miss Su is happy to cheat the man. She thinks that it was just the visa play a significant role in her marriage. What she doesn't know is that the man is customer of the matrimonial agency. He is the sparrow after the mantis. And Miss Su is trapped by the trap she designed.

There's no doubt that feminism has changed women's life. Women are no longer accessories to men. Today, women's voice is becoming more and more powerful [6]. And they are determined to create a global feminist movement. Women from all walks of life gather and fight for rights. Especially feminists, they use pens as guns to call on women to strive [7]. However, in the relationship of the couple, Miss $\mathrm{Su}$ is an accessory to the man. She has lost her agile mind, aggressive action and professional judgment. She forgets that independence is accessible for everybody [5]. What she should to is to remind herself of self-worth. The example of Miss $\mathrm{Su}$ is a warning to women.

\section{THE PLIGHT OF CONTEMPORARY FEMALE SENIOR INTELLECTUALS REFLECTED BY THE STANDARD OF SPOUSE SELECTION.}

According to the end, we are acknowledged that the man Miss Su treasured is the customer of the matrimonial agency, not the right man she is seeking for. Miss Su gets married not as she expected. Instead, she is cheated and used. The author contrives such an unhappy ending to warn people not to deceive themselves. Marriage is not as real as they think if it is forced. There is no point to change deliberately like the heroine of the novel. That's exactly the loss of subjective consciousness. The loss of subjective consciousness leads women to a worse situation [8].

The Marriage of Miss Su reflects the plight of contemporary female senior intellectuals indirectly. There are a large number of women who are labeled as $3 \mathrm{~S}$ (single, seventies, stuck) lady. The author observes social patterns and uses the $3 \mathrm{~S}$ lady label to set characters. This phenomenon happens in real life. Women are often treated in an unjust way [9]. In the novel, there are all kinds of people standing for different attitudes towards women. Miss Su stands for the contemporary female senior intellectuals. She always works hard. However, society is dominated by man. Advantages like highly educated and high income turn into disadvantages. Thus most men scare and run away once they know that women are so excellent, no matter how capable they are. 


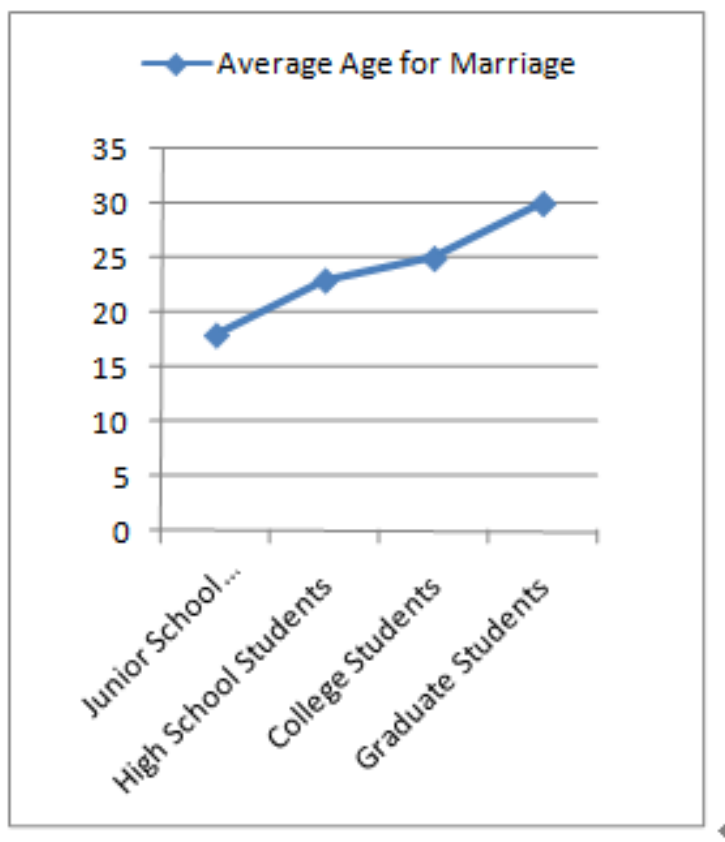

Fig. 2. Average Age for Marriage under the Influence of Education

As the figure shows, education plays an important role in average age for marriage. Women get married late when they are highly educated. On the one hand, people take education as important factor. On the other hand, women like Miss $\mathrm{Su}$ are afraid of being single, and they may disguise themselves in order to find ideal marriage.

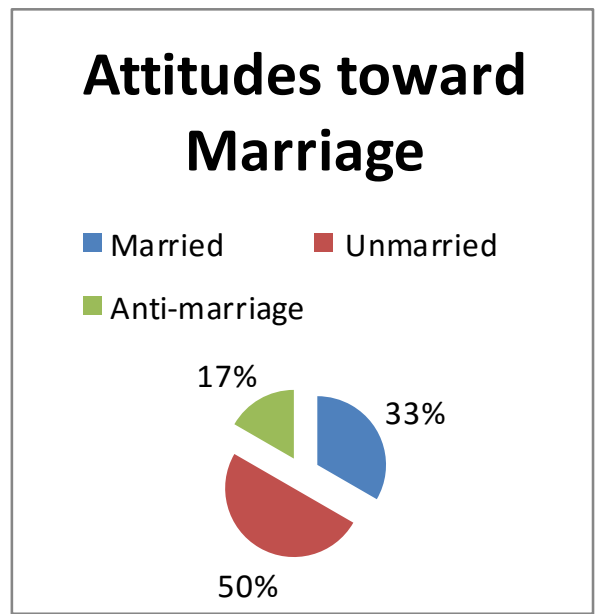

Fig. 3. Attitudes toward Marriage

Miss Su gets married in the novel. However, there are some women even change their attitudes toward marriage. The result is shown in figure above. For various reasons, they hold no hope for marriage. It is more worthy of thinking.

In spite of receiving higher education and Western education, Luoyan $\mathrm{Su}$ is not astonished at her treatment and chooses to make concession to the male-dominated society. We can come to the conclusion that women lose their status in discourse power to some extent. Women in such environment get used to it and lack of resistance consciousness.
We can also gain a hint of society's value orientation for women through the standard of spouse selection. It is gender gets women into trouble. Comparing to man, women are facing more problems [10]. In the story, all the colleagues try their best to look for an ideal marriage for Luoyan Su. After introduction, they find it difficult to do this because nobody wants to marry a woman over thirty no matter how beautiful she is. The description can be exaggerated but founded.

From figures below, it is plain to see average age for marriage changes less under the influence of time and region. It's hard to change people's opinions on women. Faced with reality, women are so vulnerable and weak that they are not strong enough to fight. In this way, women like Miss Su have no choice but to compromise.

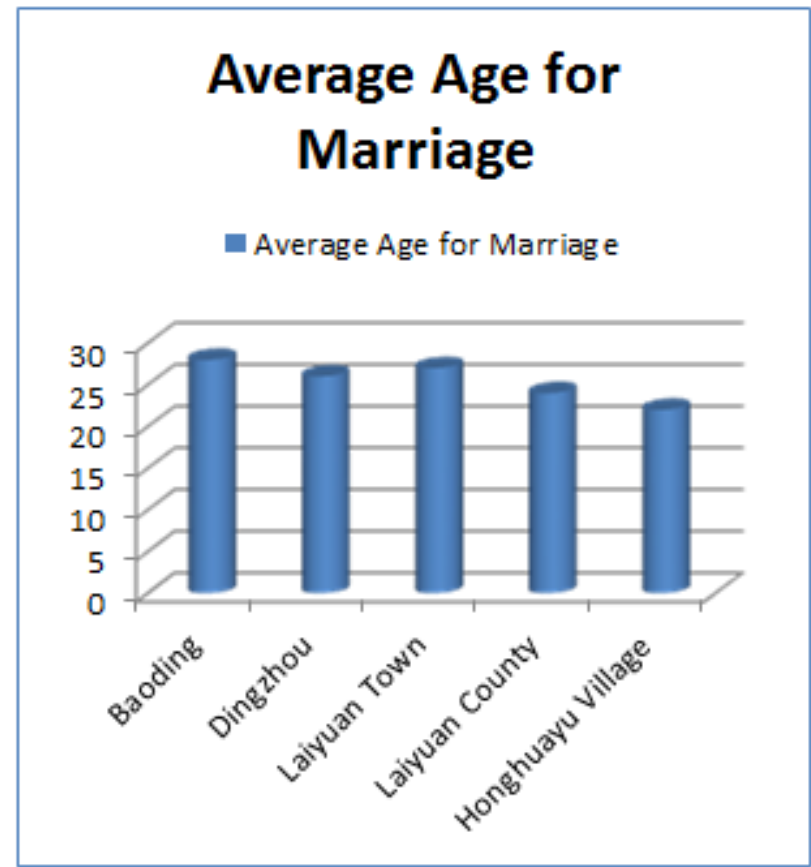

Fig. 4. Average Age for Marriage under the Influence of Region

\section{Average Age for Marriage}

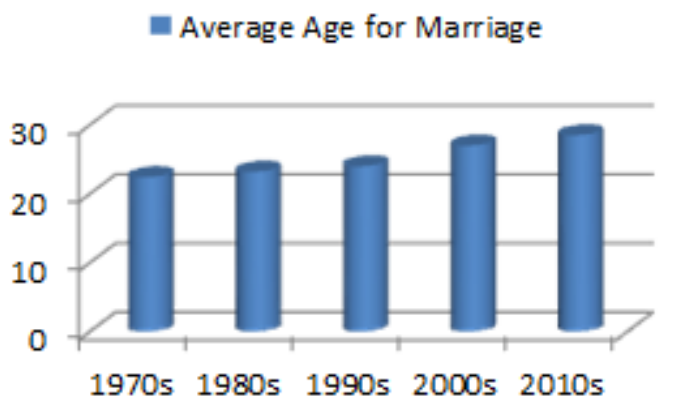

Fig. 5. Average Age for Marriage under the Influence of Time 
Women are susceptible to ages. The rich and single man in the Marriage of Miss Su is such an extreme example. Xiaopei introduces Luoyan Su to him, but he refuses because he thinks women in good condition must have other fatal defects and he wants to meet girls less than twenty-one years old. Perhaps it's just a joke, on the other hand, we can get a glimpse of popular opinion about women in society. That is age is the most critical factor not ability or character. Age is the stepping stone and older women have no choice. At the same time, Luoyan Su lowers her standard constantly. At last, Miss Su looks for anyone who is handsome and single instead of taking her own feelings as the standard. She gets married just in order to get married. Another representative example is Luoyan Su's husband. His name was not mentioned in the story and he is just a symbolic portrayal. What we know about him is just he works in IT industry. Although there is not much description, we can surely speculate the man is dominant in the relationship of the couple. Miss Su never considers her own feelings, and what she did is around that little man. Therefore, she indulges in superstars and popular novels. She even changes her clothes before she meets him in order to narrow the gap. It is self-evident that people consider age as a significant factor in marriage. Even more frightening is that these contemporary female senior intellectuals are not aware of this and adjust themselves to the society.

\section{CONCLUSION}

On the whole, The Marriage of Miss Su is close to life. Miss $\mathrm{Su}$ stands for the contemporary female senior intellectuals. Instead of lofty and mysterious character, she is vivid and vigorous. In this way, the problem it reflects has more practical significance. Miss Su will be sought after by both men and women if she was a real woman in our life. Today, feminism has an impact on our daily life more or less.
Comparing to the past, women's subjective consciousness has made a great progress. However, the habit of compromise is not changed. Women like Miss Su pursuit their own value and improve themselves continuously. At the same time, they are easy to become appendages to men. They are highly educated but also couldn't escape the trap. In order to get the approval of others (especially men), these contemporary female senior intellectuals adjust themselves to the man-dominant society. Thus it can be seen that women are vulnerable members of our society. They are usually lack of subjective consciousness and couldn't get rid of male-centralism. Much more should be done to fight for women's rights. If women want to develop independently and design their own life, there is still a long way to go.

\section{REFERENCES}

[1] Liuliu. The Marriage of Miss Su [M]. Changjiang Literature Press, 2011.

[2] Josephine Donovan. Feminist Theory [M]. Continuum Publishing Corporation, 2012

[3] Virginia Woolf. A Room of One's Own [M]. Mariner Books, 1989

[4] Sarah L. Henderson, Alana S. Jeydel. Women and Politics in a Global World [M]. Oxford University Press, 2013

[5] Bell Hooks. Feminism is for Everybody: Passionate Politics [M]. South End Press, 2000

[6] Bell Hooks. Feminist Theory: from Margin to Center [M]. Routledge, 2014

[7] Susan Sniader Lanser. Fictions of Authority: Women Writers and Narrative Voice [M]. Cormell University Press, 1992

[8] Kathleen D. McCarthy (ed). Women, Philanthropy, and Civil Society [C]. Indiana University Press, 2001.

[9] Roslyn Muraskin. Women and Justice: Development of International Policy [M]. Gordon and Breach Publishers, 1999

[10] Judith Butler. Gender Trouble: Feminism and the Subversion of Identity [M]. Routledge, 2006 